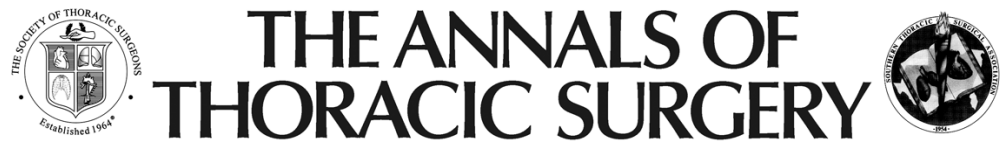

\author{
Resting Energy Expenditure and Metabolic Changes After Lung Volume \\ Reduction Surgery for Emphysema \\ Tommaso Claudio Mineo, Eugenio Pompeo, Davide Mineo, Vincenzo Ambrogi, \\ Donatella Ciarapica and Angela Polito \\ Ann Thorac Surg 2006;82:1205-1211 \\ DOI: 10.1016/j.athoracsur.2006.05.030
}

The online version of this article, along with updated information and services, is located on the World Wide Web at:

http://ats.ctsnetjournals.org/cgi/content/full/82/4/1205

The Annals of Thoracic Surgery is the official journal of The Society of Thoracic Surgeons and the Southern Thoracic Surgical Association. Copyright (C) 2006 by The Society of Thoracic Surgeons. Print ISSN: 0003-4975; eISSN: 1552-6259. 


\title{
Resting Energy Expenditure and Metabolic Changes After Lung Volume Reduction Surgery for Emphysema
}

\author{
Tommaso Claudio Mineo, MD, Eugenio Pompeo, MD, Davide Mineo, MD, \\ Vincenzo Ambrogi, MD, Donatella Ciarapica, MD, and Angela Polito, MD
}

Thoracic Surgery Division, Emphysema Center, and Endocrinology Division, Tor Vergata University, and Italian National Institute for Nutrition, Rome, Italy

Background. Oxygen consumption volume $\left(\mathrm{VO}_{2}\right)$ and resting energy expenditure are increased in emphysema because of impaired respiratory function and mechanics, with greater oxygen cost of breathing and altered metabolism. We hypothesized that lung volume reduction surgery may improve energy expenditure and metabolism.

Methods. In this 1-year prospective study, 30 patients with moderate-to-severe emphysema underwent bilateral lung volume reduction surgery; 28 similar patients, who refused operation, followed a standard respiratory rehabilitation program. Oxygen consumption volume and resting energy expenditure, both corrected for fat-free mass, $\mathrm{VO}_{2}$ proportion of respiratory muscles $\left(\% \mathrm{VO}_{2} \mathrm{Resp}\right)$, respiratory quotient, and energy substrate oxidation were determined by using a calorimetric chamber with indirect methods.

Results. Only after surgery significant improvements resulted in 1-second forced expiratory volume $(+20.4 \%$, $p=0.009)$, residual volume $(-24.8 \%, p=0.001)$, diffusion-lung carbon-monoxide $(+18.4 \%, p=0.008)$, body mass index $(+5.5 \%, p=0.01)$, resting energy expenditure $(-8.2 \%, p=0.006)$, and $\% \mathrm{VO}_{2} \operatorname{Resp}(-44.1 \%, p=0.0008)$ with increase in respiratory quotient $(0.79$ versus 0.84 ,

$S^{e}$ evere emphysema is characterized by chronic hypoxia and impaired respiratory function and mechanics, with increased oxygen cost of breathing [1-3]. This condition induces greater oxygen volume consumption $\left(\mathrm{VO}_{2}\right)$ and resting energy expenditure (REE), with abnormal energy substrates utilization [4], slowly leading to catabolism, or respiratory cachexia, with weight loss despite supplemental feeding [1-8]. Additional factors such as chronic systemic inflammation, prolonged steroid therapy, secondary endocrine abnormalities, inactivity, aging, and malnutrition also contribute to this altered metabolic status with prevalent lipid oxidation and protein wasting [5-8].

Lung volume reduction surgery has been shown to be effective in improving respiratory function, exercise tolerance, quality of life, and nutritional status in properly

Accepted for publication May 11, 2006.

Address correspondence to Dr Mineo, Cattedra di Chirurgia Toracica, Università degli Studi di Roma Tor Vergata, Policlinico Universitario Tor Vergata, Roma, Viale Oxford, 81, Rome 00133, Italy; e-mail: mineo@ med.uniroma2.it. $p=0.03)$ and conversion from prevalent lipid $(44.6 \%$ versus $34.3 \%, p=0.0007)$ to prevalent carbohydrate ( $25.2 \%$ versus $42.2 \%, p=0.0006)$ metabolism. Thirteen operated on patients discontinued oral steroids, showing the most significant improvements. The remaining 17 experienced significant changes compared with the rehabilitation group despite oral steroids (resting energy expenditure $-7.0 \%$ versus $+4.1 \%$, and $\% \mathrm{VO}_{2} \operatorname{Resp}$ $-34.0 \%$ versus $+0.7 \%, p=0.001$ ). Decrease of resting energy expenditure and $\% \mathrm{VO}_{2}$ Resp correlated with reduction of residual volume ( $p=0.02$ and $p=0.001)$ and increment of body mass index $(p=0.03$ and $p=0.004)$.

Conclusions. Lung volume reduction surgery significantly decreased $\% \mathrm{VO}_{2}$ Resp and resting energy expenditure over respiratory rehabilitation and despite oral steroid therapy. Substrate oxidation changed from prevalent lipid to prevalent carbohydrate. Correlations with residual volume and nutritional status suggest that restoration of respiratory mechanics reduces energy expenditure and approximates metabolism to normal.

(Ann Thorac Surg 2006;82:1205-11) (C) 2006 by The Society of Thoracic Surgeons

selected emphysematous patients compared with medical therapy and respiratory rehabilitation $[9,10]$.

To date, little information is available about changes in energy expenditure and metabolism after lung volume reduction surgery [11]. We hypothesized that surgical therapy may ameliorate REE and metabolism by improving respiratory function and mechanics.

The aim of this study was to analyze the impact of lung volume reduction surgery compared with respiratory rehabilitation on REE and metabolism, for the first time determined by using a calorimetric chamber with indirect methods. Correlations among respiratory, nutritional, and metabolic variables were evaluated to delineate a possible explanation for the clinical improvement after surgery.

\section{Material and Methods}

\section{Study Design and Population}

This prospective study was approved by our institution's Human Research Committee. Patients with moderate-to- 
severe emphysema were recruited from July 2000 to June 2003. Written informed consent was obtained. The analysis included intragroup (baseline versus 12-month posttreatment) and intergroup (surgery versus respiratory rehabilitation) comparisons. A 12-month follow-up was considered as the most appropriate period to expect the greatest improvement and stabilization in respiratory, energetic, and metabolic variables.

Indications for lung volume reduction surgery have been previously reported [12]. Inclusion criteria required patients to be clinically stable, performing regular mild physical activity, nonsmoking for at least 3 months, and receiving a balanced diet by our dietician $(1,800 \mathrm{Kcal} /$ day). Oxygen-dependent patients or those undergoing respiratory rehabilitation in the last year, or with concomitant chronic diseases or receiving therapy capable of interfering with REE, were excluded.

Fifty-eight selected male patients, with heterogeneous, symmetric and mainly upper lobe located emphysema, were programmed for lung volume reduction surgery. Thirty patients were operated on (median age, 64.0 years; interquartile range, 58 to 68 ). The remaining 28 subjects (median age, 65.0 years; range, 60 to 68 ) refused surgery for personal reasons (psychological rejection of surgical procedure, fear of postoperative complication, lack of confidence in surgery) and were included in a standardized respiratory rehabilitation program twice during the year, which entailed 3-hour supervised sessions 5 days a week for at least 6 weeks [12].

During the year before and after treatment, median daily dosage of steroid therapy was calculated using values collected every 3 months by our medical center, which modified medical therapy considering clinical and functional findings (spirometry and arterial blood gases).

\section{Surgical Approach}

One-stage bilateral operation through four-port videothoracoscopic access was performed. The most damaged portions of the lung were reevaluated by intraoperative inspection and resected using simple nonbuttressed suture lines, possibly excising a single strip of parenchyma to reduce the lung volume of about $30 \%$ [12]. To facilitate lung reexpansion, pulmonary ligament was routinely

Table 1. Respiratory, Biochemical, and Nutritional Measurements

\begin{tabular}{|c|c|c|c|c|c|}
\hline \multirow[b]{2}{*}{ Measurements } & \multicolumn{2}{|c|}{ LVRS $(\mathrm{n}=30)$} & \multicolumn{2}{|c|}{$\mathrm{RR}(\mathrm{n}=28)$} & \multirow{2}{*}{$\begin{array}{l}\text { LVRS Vs RR } \\
\quad p \text { Value }\end{array}$} \\
\hline & Baseline & Percent Change & Baseline & Percent Change & \\
\hline Forced expiratory volume 1 second (L) & $0.91(0.76-1.09)$ & $20.4^{\mathrm{a}}$ & $0.95(0.78-1.10)$ & $6.0^{\mathrm{b}}$ & 0.0009 \\
\hline $\begin{array}{l}\text { Forced expiratory volume } 1 \text { second } \\
\quad \text { (predicted \%) }\end{array}$ & $34.2(24.6-42.0)$ & $23.8^{\mathrm{c}}$ & $35.0(28.0-45.8)$ & $5.6^{\mathrm{b}}$ & $<0.0001$ \\
\hline Residual volume pleth (L) & $4.98(4.32-6.20)$ & $-24.8^{\mathrm{c}}$ & $5.05(4.73-5.4)$ & 1.3 & $<0.0001$ \\
\hline Residual volume pleth (predicted \%) & 189 (179-228) & $-31.6^{c}$ & $194(167-219)$ & 1.5 & $<0.0001$ \\
\hline $\begin{array}{l}\text { Diffusion lung carbon monoxide (mmol/ } \\
\mathrm{kPa}^{*} \text { min) }\end{array}$ & $3.75(2.80-6.70)$ & $18.4^{\mathrm{a}}$ & $3.60(2.8-4.0)$ & 2.1 & 0.008 \\
\hline $\begin{array}{l}\text { Diffusion lung carbon monoxide } \\
\text { (predicted \%) }\end{array}$ & $50.1(38.5-56.0)$ & $17.9^{\mathrm{a}}$ & $50.3(38.9-59.0)$ & 2.5 & 0.007 \\
\hline Arterial blood oxygen pressure $(\mathrm{kPa})$ & $9.30(8.8-10.3)$ & $10.6^{\mathrm{a}}$ & $9.5(9.0-10.4)$ & $5.2^{\mathrm{b}}$ & 0.001 \\
\hline Maximal inspiratory pressure $(\mathrm{kPa})$ & $8.3(7.1-9.4)$ & $23.2^{\mathrm{c}}$ & $8.4(7.4-9.4)$ & $8.0^{\mathrm{b}}$ & 0.0007 \\
\hline Maximal expiratory pressure $(\mathrm{kPa})$ & $10.4(9.8-11.2)$ & $7.1^{\mathrm{b}}$ & $10.1(8.9-12.2)$ & 4.2 & 0.049 \\
\hline Six-minute walk test $(\mathrm{m})$ & $410(315-450)$ & $15.8^{\mathrm{a}}$ & $412(400-448)$ & $8.1^{\mathrm{a}}$ & 0.001 \\
\hline Dyspnea index (MRC scale) & $3.0(3.0-4.0)$ & $-50^{c}$ & $3.0(3.0-4.0)$ & $-25^{\mathrm{a}}$ & 0.0008 \\
\hline Total Short Form-36 (global score $0-100)^{\mathrm{d}}$ & $50.1(50.6-68.9)$ & $17.0^{\mathrm{a}}$ & $49.1(52.4-69.2)$ & 3.3 & 0.001 \\
\hline $\begin{array}{l}\text { St.George respiratory questionnaire } \\
\text { (general score } 100-0 \text { ) }\end{array}$ & $26.6(16.8-53.0)$ & $-28.5^{c}$ & $24.1(10.1-33.9)$ & $-10.3^{a}$ & 0.0006 \\
\hline Body mass index $\left(\mathrm{kg} / \mathrm{m}^{2}\right)$ & $23.1(21.8-25.3)$ & $5.5^{\mathrm{a}}$ & $22.9(22.0-24.5)$ & -1.3 & 0.01 \\
\hline Fat-free mass $(\mathrm{kg})$ & $48.9(45.5-52.5)$ & $5.9^{\mathrm{a}}$ & $50.5(45.7-53.2)$ & -2.5 & 0.0009 \\
\hline Fat mass $(\mathrm{kg})$ & $18.4(16.0-22.4)$ & $6.9^{\mathrm{a}}$ & $18.5(17.4-19.6)$ & 3.0 & 0.007 \\
\hline Albumin (g/dL) & $4.0(3.5-4.3)$ & $11.0^{\mathrm{a}}$ & $3.9(2.7-5.1)$ & 0.5 & 0.001 \\
\hline Transferrin $(\mathrm{mg} / \mathrm{dL})$ & 199 (163-270) & $9.3^{\mathrm{b}}$ & $205(176-309)$ & -1.2 & 0.007 \\
\hline Total cholesterol (mg/dL) & 133 (106-205) & $14.9^{\mathrm{a}}$ & $142(113-169)$ & -1.5 & 0.001 \\
\hline Urinary nitrogen $(\mathrm{g} / 24 \mathrm{~h})$ & $15.5(13.7-18.0)$ & $-15.0^{\mathrm{a}}$ & $15.0(13.0-19.7)$ & 6.5 & 0.0009 \\
\hline Methylprednisolone (mg/day) & $10.5(8.1-12.8)$ & $-30.7^{\mathrm{c}, \mathrm{e}}$ & $10.4(8.4-11.9)$ & $-29.3^{a}$ & NS \\
\hline
\end{tabular}

Intragroup significance: ${ }^{\mathrm{a}} p \leq 0.01 ; \quad{ }^{\mathrm{b}} p \leq 0.05 ; \quad{ }^{\mathrm{c}} p \leq 0.001 ; \quad{ }^{\mathrm{d}}$ Global score $=\left[(\text { all answer score-lowest score possible/highest score possible })^{*}\right.$ 100]; $\quad$ Values for oral steroid-continuing operated patients subset.

Patients selected for lung volume reduction surgery (LVRS) and respiratory rehabilitation (RR): intragroup (Wilcoxon test) and intergroup (MannWhitney test) comparison of 12-month posttreatment percentage changes. Data are expressed as median values and interquartile range.

MRC = Medical Research Council; $\quad$ NS = not significant. 
sectioned. Neither pleural abrasion nor tent protection were performed.

\section{Respiratory and Nutritional Evaluation}

Respiratory and functional evaluations included arterial blood gas analysis, plethysmography, 6-minute walk test, and dyspnea index [13]. Quality of life was assessed with the Medical Outcomes Study Short Form 36-Item [14] and St. George's Respiratory Questionnaire [15]. Nutritional evaluation included classic biochemical and anthropometric measurements. In addition, body composition, both fat and fat-free masses, was accurately measured by using a total body dual-energy X-ray absorptiometry (model QDR 2000; Hologic, Waltham, Massachusetts), the present gold standard for this evaluation [16].

\section{Energetic and Metabolic Assessment}

Total $\mathrm{VO}_{2}$ was defined as the summation of metabolic $\mathrm{VO}_{2}$, assumed to be constant during the measurement, and $\mathrm{VO}_{2}$ of respiratory muscles: therefore, the increment of total $\mathrm{VO}_{2}$ would reflect the increment of oxygen cost of breathing.

We measured total $\mathrm{VO}_{2}$ at rest by using a calorimetric chamber with indirect methods. Classically, indirect calorimetry requires devices unsuitable for emphysematous patients (mouthpiece, nose-clip, and canopy). In contrast, the calorimetric chamber allows patients to breath normally, providing a more accurate measurement. The examination was performed under basal conditions (after 12-hour fasting and 24-hour drug interruption). One-day urine was collected to determine daily nitrogen excretion. Every patient entered the room at 7:30 $\mathrm{AM}$ and rested in bed for a 4-hour period during the measurement. The $\mathrm{VO}_{2}$ and carbon-dioxide production $\left(\mathrm{VCO}_{2}\right)$ were measured continuously using a thermomagnetic oxygen analyzer (Magnos 4G; Hartman \& Braun, Frankfurt, Ger- many) and an infrared carbon-dioxide analyzer (Uras 3G; Hartman \& Braun), respectively, calibrated before and after each test with a mixture of gases, with a coefficient of variation of $0.9 \%$ and $1.5 \%$, respectively. The accuracy of measurements was assessed burning a weighted amount of buthane inside the chamber after each examination.

Energetic and metabolic variables were calculated according to the formula of Weir and derived equations [17, 18]: $\operatorname{REE}(\mathrm{KJ} / 24 \mathrm{~h})=\left\{\left[\left(\mathrm{VO}_{2}{ }^{*} 3.94\right)+\left(\mathrm{VCO}_{2}{ }^{*} 1.10\right)\right]^{*} 1.44\right\}-$ $\left(2.17^{*} \text { urinary nitrogen }\right)^{*} 4.186$; respiratory quotient $=\mathrm{VCO}_{2} /$ $\mathrm{VO}_{2}$; nonprotein respiratory quotient $=\left(1.44^{*} \mathrm{VCO}_{2}\right.$ $4.89^{*}$ urinary nitrogen $) /\left(1.44^{*} \mathrm{VO}_{2}-6.04^{*}\right.$ urinary nitrogen).

Energy substrate oxidation was calculated according to the following formulas [19]: carbohydrates $(\mathrm{g} / 24 \mathrm{~h})=$ $\left(5.926 * \mathrm{VCO}_{2}-4.189 * \mathrm{VO}_{2}-2.539 *\right.$ urinary nitrogen); proteins $(\mathrm{g} / 24 \mathrm{~h})=\left(6.25^{*}\right.$ urinary nitrogen); lipids $(\mathrm{g} / 24 \mathrm{~h})=$ $\left(2.432 * \mathrm{VCO}_{2}-2.432 * \mathrm{VO}_{2}-1.943 *\right.$ urinary nitrogen $)$ and expressed as percentage values of their relative utilization.

Respiratory muscles $\mathrm{VO}_{2}$ was calculated as the proportion of $\mathrm{VO}_{2}$ of respiratory muscles compared with the total $\mathrm{VO}_{2}\left(\% \mathrm{VO}_{2}\right.$ Resp $)$ from the measured and the predicted REE values, according to the formula proposed by Takayama and coworkers [11]: $\% \mathrm{VO}_{2} \operatorname{Resp}=\mathrm{REE}$ measured $-0.98 *$ REE predicted/REE measured ${ }^{*} 100$. In this formula, resting $\mathrm{VO}_{2}$ Resp in normal subjects was assumed equal to $2 \%$, and the predicted REE was calculated using the Harris and Benedict equation [18]: REE predicted $(\mathrm{KJ} / 24 \mathrm{~h})=\left[66.46+13.75^{*}\right.$ (weight) + $5.04^{*}$ (height) $-6.76^{*}$ (age) $]^{*} 4.186$.

The REE and $\mathrm{VO}_{2}$ were corrected for fat-free mass to better evaluate the effective metabolism in the most active body district (muscle tissue), to avoid underestimation, and to normalize all data for group comparison [8].

Measurements of the calorimetric chamber were matched and validated in a healthy population of the

Table 2. Energetic and Metabolic Measurements

\begin{tabular}{|c|c|c|c|c|c|}
\hline \multirow[b]{2}{*}{ Measurements } & \multicolumn{2}{|c|}{$\operatorname{LVRS}(\mathrm{n}=30)$} & \multicolumn{2}{|c|}{$\mathrm{RR}(\mathrm{n}=28)$} & \multirow{2}{*}{$\begin{array}{c}\text { LVRS Vs RR } \\
p \text { Value }\end{array}$} \\
\hline & Baseline & Percent Change & Baseline & Percent Change & \\
\hline $\mathrm{VO}_{2}(\mathrm{~mL} / \mathrm{min})$ & $232(205-243)$ & $-5.7^{\mathrm{a}}$ & $233(212-254)$ & 1.3 & $<0.0001$ \\
\hline $\mathrm{VO}_{2} /$ fat-free mass $(\mathrm{mL} / \mathrm{kg} / \mathrm{min})$ & $4.72(4.38-5.05)$ & $-9.1^{b}$ & $4.60(4.03-5.29)$ & 4.5 & $<0.0001$ \\
\hline$\% \mathrm{VO}_{2} \operatorname{Resp}(\%)$ & $11.3(2.31-18.7)$ & $-44.1^{\mathrm{c}}$ & $10.2(1.03-20.7)$ & 1.8 & $<0.0001$ \\
\hline REE predicted $(\mathrm{kJ} / 24 \mathrm{~h})$ & $5831(5423-6477)$ & $4.8^{\mathrm{a}}$ & $5929(5567-6441)$ & -0.6 & 0.0009 \\
\hline $\operatorname{REE}(\mathrm{kJ} / 24 \mathrm{~h})$ & $6630(5867-6957)$ & $-4.9^{\mathrm{a}}$ & $6712(6046-7146)$ & 1.2 & 0.001 \\
\hline REE/fat-free mass (kJ/kg/24h) & $134(123-145)$ & $-8.2^{b}$ & $131(115-153)$ & 4.2 & 0.0007 \\
\hline Respiratory quotient & $0.79(0.79-0.82)$ & $4.3^{\mathrm{a}}$ & $0.79(0.79-0.83)$ & 0.5 & 0.006 \\
\hline Nonprotein respiratory quotient & $0.79(0.79-0.82)$ & $5.2^{\mathrm{a}}$ & $0.79(0.74-0.83)$ & 0.8 & 0.007 \\
\hline Carbohydrates (g/24h) & $100.0(84-111)$ & $43.3^{c}$ & $102(102-111)$ & 1.4 & $<0.0001$ \\
\hline Lipids (g/24h) & $78.9(67.7-88.5)$ & $-30.2^{c}$ & $73.2(68.1-82.4)$ & -2.1 & 0.001 \\
\hline Proteins (g/24h) & $96.8(81-113)$ & $-15.2^{b}$ & $93.8(85-99)$ & 6.5 & 0.008 \\
\hline
\end{tabular}

Intragroup significance: ${ }^{\mathrm{a}} p \leq 0.05 ; \quad{ }^{\mathrm{b}} p \leq 0.01 ; \quad{ }^{\mathrm{c}} p \leq 0.001$.

Patients selected for lung volume reduction surgery (LVRS) and respiratory rehabilitation (RR): intragroup (Wilcoxon test) and intergroup (MannWhitney test) comparison of 12-month posttreatment percentage changes. Data are expressed as median values and interquartile range.

$\mathrm{REE}=$ resting energy expenditure; $\quad \% \mathrm{VO}_{2} \mathrm{Resp}=$ proportion of oxygen consumption consumed by respiratory muscles; $\mathrm{VO}_{2}=$ oxygen consumption. 
same age and sex, using values obtained by a traditional indirect calorimeter with canopy device (Deltatrac II MBM-200; Datex-Ohmeda, Datex-Engstrom Instrumentarium, Helsinki, Finland). These values resulted not statistically different from those measured with the chamber.

\section{Statistic Evaluation}

Descriptive statistics were presented as median and interquartile ranges, while posttreatment changes were indicated as the median percentage of the baseline value. Owing to the nonnormal distribution of some variables and the relative small sample size, nonparametric tests for paired (Wilcoxon) and unpaired (Mann-Whitney) comparisons were used (SPSS 9.05 version, Chicago, Illinois). In the surgical group, correlations (Spearman) among respiratory, nutritional, energetic, and metabolic variables were performed using postoperative percentage changes.

\section{Results}

\section{Intragroup (Baseline to 12-Month Posttreatment) Evaluation}

All patients in both groups were available for a 12-month follow-up. None of the operated on patients underwent respiratory rehabilitation in the year of follow-up. After

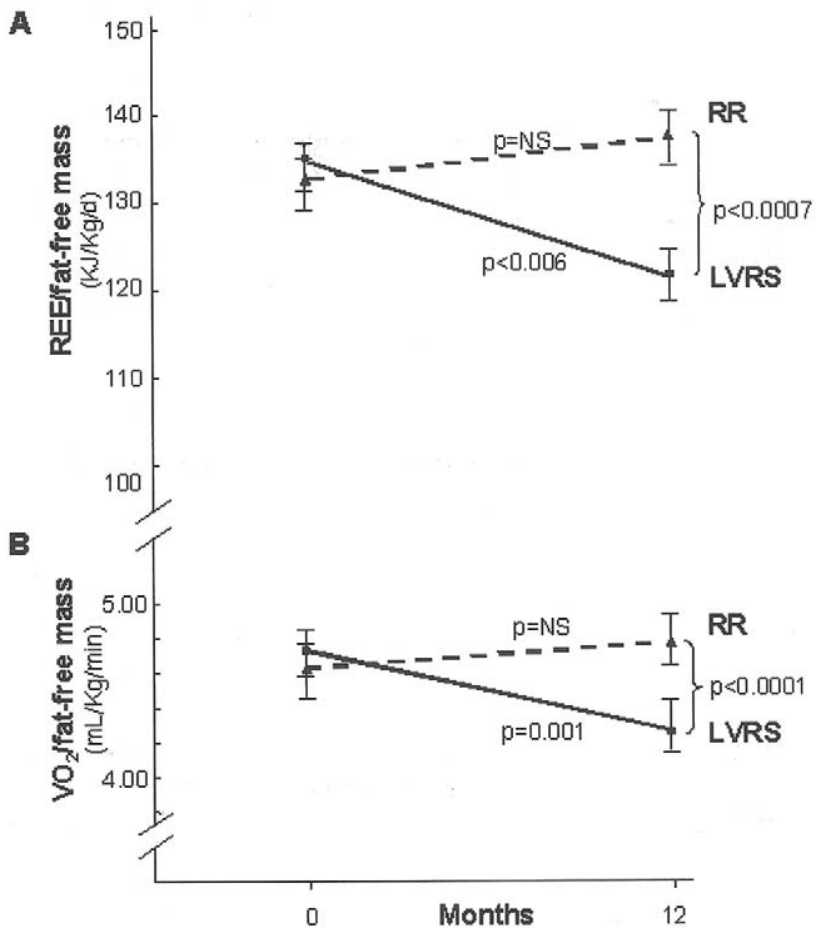

Fig 1. Median absolute values of (A) resting energy expenditure (REE/ fat-free mass) and (B) oxygen consumption $\left(\mathrm{VO}_{2} /\right.$ fat-free mass), after lung volume reduction surgery (LVRS) and respiratory rehabilitation (RR). The $p$ values of intragroup comparisons (Wilcoxon, near lines) and intergroup comparisons (Mann-Whitney, near brackets) are reported. Bars represent interquartile ranges. (NS = not significant.)
LVRS pre

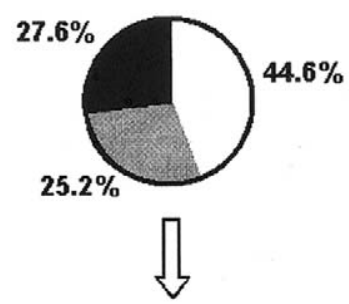

$24.1 \%$

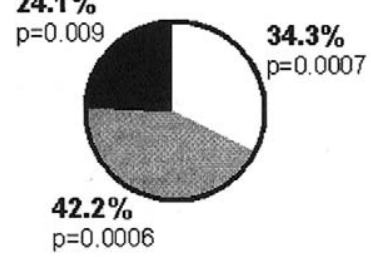

LVRS post

\section{RR pre}
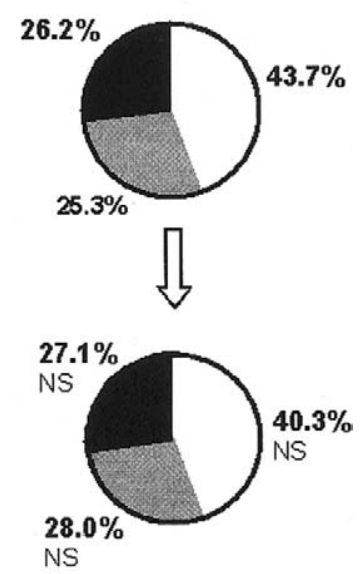

RR post
Fig 2. Median percentage values of energy substrate utilization rate after lung volume reduction surgery (LVRS) and respiratory rehabilitation (RR). Significances of posttreatment intragroup (Wilcoxon test) comparisons are reported. (White areas = lipids; gray areas $=$ carbohydrates; black areas $=$ proteins; $N S=$ not significant; Post $=$ postoperative; Pre $=$ preoperative.)

surgery, significant improvements were found in the majority of respiratory, symptomatic, and nutritional variables (Table 1): 1-second forced expiratory volume $(+20.4 \%, p=0.009)$, residual volume $(-24.8 \%, p=0.001)$, diffusion lung carbon monoxide $(+18.4 \%, p=0.008)$, body mass index $(+5.5 \%, p=0.01)$, fat-free mass $(+5.9 \%$, $p=0.005)$, and fat mass $(+6.9 \%, p=0.004)$. The $\mathrm{VO}_{2}$ and REE were significantly reduced (Table 2, Fig 1), especially when corrected for fat-free mass $(-9.1 \%, p=0.001$ and $-8.2 \%, p=0.006$, respectively); similarly, $\% \mathrm{VO}_{2} \operatorname{Resp}$ showed a relevant decrement $(-44.1 \%, p=0.0008)$. Respiratory quotient presented a moderate increment ( 0.79 versus $0.84, p=0.03$ ) with conversion of energy substrate utilization (Fig 2) from prevalent lipid $(44.6 \%$ versus $34.3 \%, p=0.0007$ ) to prevalent carbohydrate $(25.2 \%$ versus $42.2 \%, p=0.0006)$ metabolism with moderate protein sparing $(27.6 \%$ versus $24.1 \%, p=0.009)$.

After respiratory rehabilitation, only some respiratory and symptomatic variables improved while metabolic and nutritional parameters remained substantially stable (Tables 1 and 2, Fig 1). Respiratory quotient and substrate utilization confirmed after treatment an abnormal prevalent lipid metabolism $(43.7 \%$ versus $40.3 \%)$ in comparison with carbohydrate $(25.3 \%$ versus $28.0 \%)$ with mild protein depletion (26.2\% versus $27.1 \%$; Fig 2).

\section{Intergroup (Surgical Versus Respiratory Rehabilitation) Evaluation}

At baseline, no statistical differences were found between surgical and rehabilitation groups in respiratory, nutritional, and metabolic variables, confirming the homogeneity of the two populations. As expected, emphysema- 
tous patients showed greater REE and lower respiratory quotient with altered substrate utilization respect to the healthy population, with a normal mixed metabolism (respiratory quotient around 0.85 ) and a prevalent carbohydrate metabolism.

Twelve months after treatment, the operated on patients revealed significant improvement in respiratory, nutritional, and metabolic variables in comparison with rehabilitated ones, approximating the healthy group. In particular, $\mathrm{VO}_{2}$ and REE significantly decreased, with $\% \mathrm{VO}_{2}$ Resp considerably reduced. Energy substrate utilization returned to a more physiologic prevalent carbohydrate oxidation with respiratory quotient approximating normal (Tables 1 and 2, Figs 1 and 2).

\section{Steroid Therapy Evaluation}

At baseline, the surgical and the respiratory rehabilitation groups were closely matched for median oral steroid daily dosage: methylprednisolone $10.5 \mathrm{mg}$ /day (interquartile range, 8.1 to $12.8 \mathrm{mg} /$ day) and $10.4 \mathrm{mg} /$ day ( 8.4 to $11.9 \mathrm{mg} /$ day), respectively.

After surgery, 13 patients discontinued oral steroid therapy (oral steroid discontinuing, baseline value 10.4 $\mathrm{mg} /$ day); the remaining 17 operated on subjects significantly reduced the median daily dosage (oral steroid continuing: baseline value $10.5 \mathrm{mg} /$ day; posttreatment change $-30.7 \%, p=0.0004)$. After rehabilitation, none of the patients was able to discontinue oral steroids, although a significant reduction $(-29.3 \%, p=0.0005)$ in the median daily dosage was achieved (Table 1).

The inhaled steroid and beta ${ }_{2}$-agonist therapy in both groups remained unchanged after treatment and during the entire year of follow-up: beclomethasone $1.3 \mathrm{mg} /$ day (1.2 to $1.5 \mathrm{mg} /$ day) or budesonide $580 \mu \mathrm{g} /$ day (540 to 610 $\mu \mathrm{g} /$ day); salbutamol $345 \mu \mathrm{g} /$ day (325 to $387 \mu \mathrm{g} /$ day) or formeterol $40 \mu \mathrm{g} /$ day (34 to $47 \mu \mathrm{g} /$ day).

To evaluate the impact of oral steroids on REE and metabolism, we analyzed the operated on patients who were able to discontinue oral steroids and those who continued. This last subset of patients was also compared with the respiratory rehabilitation group.

At baseline, no statistical differences were found among the two subsets of the surgical group and the respiratory rehabilitation one, either in respiratory, nutritional, and metabolic variables or in the oral steroid dosage.

Twelve months after treatment, the operated on patients who discontinued oral steroids showed the most significant improvement in the evaluated variables. Interestingly, the operated on patients who continued oral steroids experienced significant changes compared with the respiratory rehabilitation ones, although differences of dosage between these two groups were not significant: 1 -second forced expiratory volume $(+18.6 \%$ versus $+6.0 \%, p=0.005)$, residual volume $(-22.9 \%$ versus $+1.3 \%, p=0.0008)$, diffusion lung capacity for carbon monoxide $(+17.2 \%$ versus $+2.1 \%, p=0.001)$, body mass index $(+4.3 \%$ versus $-1.3 \%, p=0.04)$, fat-free mass $(+4.2 \%$ versus $-2.5 \%, p=0.01)$, fat mass $(+5.1 \%$ versus $+3.0, p=0.03), \mathrm{VO}_{2}$ adjusted for fat-free mass $(-7.3 \%$
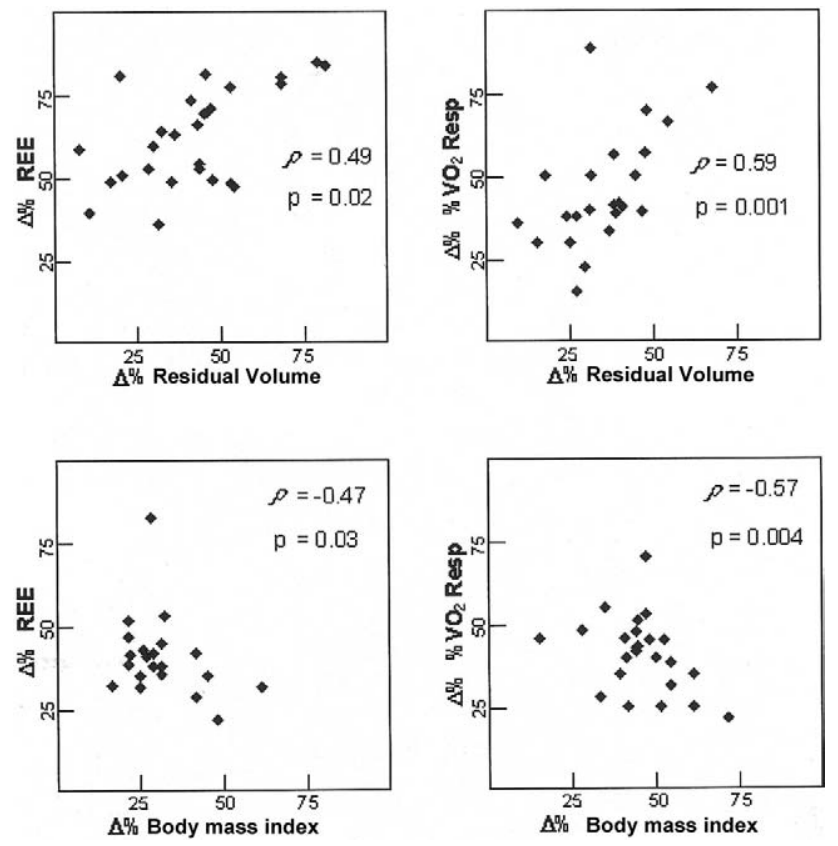

Fig 3. Correlations (Spearman) among main respiratory (residual volume), nutritional (body mass index), and metabolic (proportion of $\mathrm{VO}_{2}$ consumed by respiratory muscles [ $\% \mathrm{VO}_{2}$ Resp] and resting energy expenditure [REE]) variables in the surgical group. Correlation coefficient rho $(\rho)$ and significances ( $p$ value) are reported.

versus $+4.5 \%, p=0.005)$, REE adjusted for fat-free mass $(-7.0 \%$ versus $+1.2 \%, p=0.001), \% \mathrm{VO}_{2} \operatorname{Resp}(-34.0 \%$ versus $+1.8 \%, p=0.001)$, and respiratory quotient $(+4.2 \%$ versus $0.5 \%, p=0.007)$. Energy substrate utilization also presented significant changes in carbohydrate $(+31.2 \%$ versus $+1.4 \%, p=0.001)$, lipid $(-19.2 \%$ versus $-2.1 \%, p=0.001)$, and protein $(-9.9 \%$ versus $+6.5 \%, p=$ 0.01 ) oxidation.

\section{Correlation Analysis}

In the surgical group, the improvements in respiratory function were positively correlated with the amelioration of metabolic and anthropometrics parameters (Fig 3). Namely, the decrements of REE and $\% \mathrm{VO}_{2}$ Resp were significantly correlated with the reduction of residual volume $(\rho=0.49$, $p=0.02$ and $\rho=0.59, p=0.001$, respectively) and with the increment of body mass index $(\rho=-0.47, p=0.03$ and $\rho=$ $-0.57, p=0.004$, respectively). Moderate significance was also found between REE and 1-second forced expiratory volume $(\rho=-0.48, p=0.02)$, whereas mild significance was found with diffusion lung capacity for carbon monoxide $(\rho=-0.42, p=0.04)$ or fat-free mass $(\rho=-0.38, p=0.05)$. Only marginal significances were found between REE and maximal inspiratory pressure $(\rho=-0.31, p=0.07)$, or 6-minute walk test $(\rho=-0.30, p=0.07)$ or St.George's Respiratory Questionnaire $(\rho=0.28, p=0.08)$.

\section{Comment}

In severe emphysema, REE is increased as much as $20 \%$ of the normal, especially in malnourished patients, as a 
result of an inefficient and expensive work of breathing [1-8]. Indeed, chronic hypoxia and impaired respiratory mechanics, secondary to airways obstruction, pulmonary destruction, and increased residual volume, induce the activation of disadvantageous accessory respiratory muscles with supplementary $\mathrm{VO}_{2}$ and greater REE. This hypermetabolic condition, with progressive imbalance between "oxygen requirement and availability," determines an abnormal energetic substrates utilization, slowly leading to catabolism and respiratory cachexia, despite increased caloric intake [7, 8]. Furthermore, enhanced levels of inflammatory cytokines (ie, tumor necrosis factor-alpha) [20], prolonged medical therapy (mainly steroids), and peculiar hormonal abnormalities (ie, reduction of sex steroids and increment of glucocorticoids) [21] increase depletion of both fat and fat-free masses $[7,8]$ and contribute to a suboptimal utilization of carbohydrates [22], with change to prevalent lipid oxidation, protein wasting, and decrement of the respiratory quotient [5-8]. Finally, mastication, swallowing, and gastric filling worsen dyspnea and hypoxia, inducing anorexia and malnutrition [5, 7].

Lung volume reduction surgery provides immediate and prolonged improvement of static volumes, exercise capacity, quality of life, and nutritional status over maximal medical and rehabilitation therapy [9, 10, 23-27]. All these changes appeared correlated with the surgical reduction of residual volume [12, 25-27].

Changes in energy expenditure and metabolism after lung volume reduction surgery have been poorly investigated. Recently, in a 3-month prospective study on end-stage malnourished emphysematous patients, Takayama and colleagues [11] showed that lung surgery, mainly unilateral, reduced energy expenditure of respiratory muscles only during exercise, by decreasing small airway obstruction and lung hyperinflation. Pulmonary function and $\mathrm{VO}_{2}$ were measured by using a method of continuous expiratory dead space [28] while $\% \mathrm{VO}_{2}$ Resp was indirectly calculated from the measured energy expenditure and the predicted values.

In this prospective study, we report the 12-month results after bilateral lung volume reduction surgery in 30 well-nourished patients with moderate-to-severe emphysema compared with an homogeneous group of patients receiving respiratory rehabilitation therapy. Resting energy expenditure and metabolism were evaluated for the first time by using a calorimetric chamber with indirect methods. In addition, nutrional status was more accurately evaluated in comparison with our previous studies $[26,27]$ by using dual-energy X-ray absorptiometry for body composition, both fat and fat-free mass.

We observed that only surgery significantly reduced REE, $\mathrm{VO}_{2}$, and $\% \mathrm{VO}_{2}$ Resp, improved respiratory quotient with change from prevalent lipid to prevalent carbohydrate metabolism, and restored body composition. Correlation analysis suggested that postoperative improvement of respiratory function and mechanics positively influences oxygen cost of breathing and energy expenditure, thus modifying substrate utilization and improving metabolism and nutritional status. In fact, the decrement of $\% \mathrm{VO}_{2}$ Resp and REE seemed correlated with the reduction of residual volume and the increment of body mass index.

The reduction of residual volume and thoracic hyperinflation implies the recuperation of proper respiratory muscles function and mechanics. The recruitment of new alveolar capacity and supplementary pulmonary microcircles ameliorates gas exchanges. These events disrupt the compensatory but inefficient work of breathing, thus reducing the respiratory and metabolic overload, save REE, and restore a positive energy balance. The increased oxygen availability and the reduced oxygen cost favor an appropriate substrate utilization, with a more physiologic prevalent carbohydrate metabolism, an increment of respiratory quotient, and a recovery in body composition, both fat and fat-free masses.

The correlations between REE and the amelioration of 1-second forced expiratory volume, diffusion lung capacity for carbon monoxide, and fat-free mass supported this statement. Recuperation of metabolic efficiency may contribute to the recovery of exercise tolerance and the return to a normal daily activity, thus explaining the marginal correlations between REE and some functional and quality of life-related variables.

Respiratory rehabilitation therapy did not modify pulmonary static volumes, thus producing only mild improvement of respiratory mechanics and gas exchanges despite the reduction of oral steroids. The persistent breathing overload and oxygen imbalance maintain the hypermetabolic-catabolic status with elevated REE and altered metabolism.

Interestingly, only surgery allowed the suspension of oral steroids. Patients who completely discontinued oral steroids showed the most significant changes, whereas those who continued oral steroids, even at lower doses, exhibited more significant improvements than respiratory rehabilitation patients. This finding confirms the negative effects of oral steroids on metabolic and nutritional variables, outlining a role of surgery per se in restoring REE and metabolism.

Limitations of the study may be represented by the nonrandomized nature of the trial, although the homogeneity at baseline of the two arms of the study group was statistically proven. The relatively small sample size did not allow appropriate dose-dependent and categoric analyses for oral steroid therapy. The evaluation of the effect of inhaled steroids and beta ${ }_{2}$-agonists that could potentially affect energy expenditure was marginal. The role of metabolic hormones and inflammatory mediators in the systemic complication of severe emphysema was not investigated. Furthermore, the results were limited to a short period of observation, and the long-term effects of surgery on energy expenditure and metabolism were not available. A randomized controlled trial for at least 3-year period would be desirable to reinforce our data.

In conclusion, we found that lung volume reduction surgery significantly reduces REE by decreasing $\% \mathrm{VO}_{2}$ Resp with increment of respiratory quotient and return to a prevalent carbohydrate metabolism. These improvements are not found in patients treated by respi- 
ratory rehabilitation, and occurred despite oral steroid therapy. Correlations with residual volume and nutritional status suggest that the restoration of respiratory function and mechanics reduces energy expenditure and approximates metabolism to normal, representing a possible explanation for the clinical improvement after surgery.

This research was funded by the MURST COFIN Grants 9906274194-06 and 2001061191-001, CNR CU0100935CT26 2002, and Centro di Eccellenza 2001.

\section{References}

1. Hugli O, Schutz Y, Fitting JW. The daily energy expenditure in stable chronic obstructive pulmonary disease. Am J Respir Crit Care Med 1996;153:294-300.

2. Shindoh C, Hida W, Kikuchi Y, et al. Oxygen consumption of respiratory muscle in patients with COPD. Chest 1994;105: $790-7$.

3. Mannix ET, Manfredi F, Farber MO. Elevated $\mathrm{O}_{2}$ cost of ventilation contributes to tissue wasting in COPD. Chest 1999;115:708-13.

4. Donahoe M, Rogers RM, Wilson DO, Pennock BE. Oxygen consumption of the respiratory muscles in normal and in malnourished patients with chronic obstructive pulmonary disease. Am Rev Respir Dis 1989;140:385-91.

5. Congleton J. The pulmonary cachexia syndrome: aspects of energy balance. Proc Nutr Soc 1999;58:321-8.

6. Wouters EF. Nutrition and metabolism in COPD. Chest 2000;117(Suppl):274-80.

7. Schols AMWJ, Soeters PB, Mostert R, Wouters EFM. Energy balance in chronic obstructive pulmonary disease. Am Rev Respir Dis 1991;143:1248-52.

8. Baarends EM, Schols AMWJ, Pannemans DLE, Westerterp KR, Wouters EFM. Total free energy expenditure in patients with severe chronic obstructive pulmonary disease. Am J Respir Crit Care Med 1997;155:549-54.

9. Yusen RD, Lefrak SS, Gierada DS, et al. A prospective evaluation of lung volume reduction surgery in 200 consecutive patients. Chest 2003;123:1026-37.

10. National Emphysema Treatment Trial Research Group. A randomized trial comparing lung volume reduction surgery with medical therapy for severe emphysema. N Engl J Med 2003;348:2059-73.

11. Takayama T, Shindoh C, Kurokawa Y, et al. Effects of lung volume reduction surgery for emphysema on oxygen cost of breathing. Chest 2003;123:1847-52.

12. Pompeo E, Marino M, Nofroni I, Matteucci G, Mineo TC. Reduction pneumoplasty versus respiratory rehabilitation in severe emphysema: a prospective randomized study. Ann Thorac Surg 2000;70:948-53.

13. Task Group on Screening for Respiratory Disease in Occupational Setting. Official statement of the American Thoracic Society. Am Rev Resp Dis 1982;126:952-6.

14. Ware JE, Snow KK, Kosinski M. SF-36 Health Survery. Manual and interpretation guide. Lincoln, RI: Quality Metric Incorporated, 1993.

15. Jones PW, Quirk FH, Baveystock CM, Littlejohns P. A self-complete measure of health status for chronic airflow limitation: the S.George's respiratory disease questionnaire. Am Rev Resp Dis 1992;145:1321-27.

16. Steiner MC, Barton RL, Singh SJ, Morgan MD. Bedside methods versus dual energy X-ray absorptiometry for body composition measurement in COPD. Eur Respir J 2002;19:626-31.

17. Weir JB. New methods for calculating metabolic rate with special reference to protein metabolism. 1949. Nutrition 1990;6:213-21.

18. Harris JA, Benedict FG. A biometric study of the basal metabolism in men. Washington, DC: Carnegie Institute, 1919.

19. Takala J, Merilainen P. Handbook of gas exchange and indirect calorimetry. Document n.876710-1. Datex-Ohmeda Corp, Helsinki, Finland.

20. De Gody I, Calhoun WJ, Donahoe M, Mancino J, Rogers RM. Cytokine production by peripheral blood monocytes of COPD patients. Am J Respir Crit Care Med 1994;149:1017.

21. Biskobing DM. COPD and osteoporosis. Chest 2002;121: 609-20.

22. Lehninger AL. Electron transport, oxidative phosphorylation, and regulation of ATP production. In: Lehninger AL, ed. Principles in biochemistry. New York: Worth, 1982:467-505.

23. Criner GJ, Cordova FC, Furukawa S, et al. Prospective randomized trial comparing bilateral lung volume reduction surgery to pulmonary rehabilitation in severe chronic obstructive pulmonary disease. Am J Respir Crit Care Med 1999;160:2018-27.

24. Geddes D, Davies M, Koyama $\mathrm{H}$, et al. Effect of lungvolume-reduction surgery in patients with severe emphysema. N Engl J Med 2000;343:239-45.

25. Mineo TC, Ambrogi V, Pompeo E, et al. Impact of lung volume reduction surgery versus rehabilitation on quality of life. Eur Resp J 2004;23:275-80.

26. Mineo TC, Ambrogi V, Pompeo E, Bollero P, Mineo D, Nofroni I. Body weight and nutritional changes after reduction pneumoplasty in severe emphysema: a randomized study. J Thorac Cardiovasc Surg 2002;124:660-7.

27. Mineo TC, Ambrogi V, Mineo D, et al. Bone mineral density improvement after lung volume reduction surgery for severe emphysema. Chest 2005;127:1960-6.

28. Takishima T, Shaindoh C, Kikuchi $Y$, et al. Aging effect on oxygen consumption of respiratory muscles in humans. J Appl Physiol 1990;69:14-20. 


\section{Resting Energy Expenditure and Metabolic Changes After Lung Volume Reduction Surgery for Emphysema}

Tommaso Claudio Mineo, Eugenio Pompeo, Davide Mineo, Vincenzo Ambrogi, Donatella Ciarapica and Angela Polito

Ann Thorac Surg 2006;82:1205-1211

DOI: 10.1016/j.athoracsur.2006.05.030

\section{Updated Information \& Services}

\section{References}

Citations

Subspecialty Collections

Permissions \& Licensing

Reprints including high-resolution figures, can be found at: http://ats.ctsnetjournals.org/cgi/content/full/82/4/1205

This article cites 24 articles, 14 of which you can access for free at: http://ats.ctsnetjournals.org/cgi/content/full/82/4/1205\#BIBL

This article has been cited by 3 HighWire-hosted articles: http://ats.ctsnetjournals.org/cgi/content/full/82/4/1205\#otherarticle S

This article, along with others on similar topics, appears in the following collection(s):

Lung - other

http://ats.ctsnetjournals.org/cgi/collection/lung_other

Requests about reproducing this article in parts (figures, tables) or in its entirety should be submitted to:

http://www.us.elsevierhealth.com/Licensing/permissions.jsp or email: healthpermissions@elsevier.com.

For information about ordering reprints, please email: reprints@elsevier.com 